\title{
Research on Formation Mechanism of Jiyang Shallow Saline Ground Water
}

\author{
Zhang Fengjuan ${ }^{1}$, Xing Liting ${ }^{*}, 1$, Wang Song ${ }^{2}$, Zhuang Huibo ${ }^{2}$, Dou Tongwen ${ }^{3}$ and Yang Zengyuan ${ }^{3}$ \\ ${ }^{I}$ College of Resources and Environment, University of Jinan, Jinan, 250022, China \\ ${ }^{2}$ Hydrographic Office of Shandong Province, Jinan, 250002, China \\ ${ }^{3}$ Hydrographic Office of Jinan City, Jinan, 250013, China
}

\begin{abstract}
Shallow salt water in the inland plain has huge development potential. Taking saline water area in Sungeng Town, Jiyang County as an example, based on field water quality and water table tests., tracing test, methods such as mathematical statistical, hydrochemistry diagram of piper and numerical simulation by PHREEQC are used to analyze synthetically. 6862 groups data were studied. Results showed: (1) The groundwater presents typically "weather evaporation" type, chemistry type is $\mathrm{Cl}_{\mathrm{SO}}$ - Mg.Na. and Cl.SO $\mathrm{S}_{4} \mathrm{Na} . \mathrm{Mg}$ type. (2) In area of inland saline water presents characteristics of lagging water flow with high clay content in aquifer medium. Groundwater mineralization is obvious. (3) Hydrogeochemistry actions such as evaporation, alternate adsorption and water-rock interaction are the primary cause of the forming complex hydrochemistry type. The unique groundwater circulation characteristics of inland plains saltwater area makes water dynamic being relatively stable.
\end{abstract}

Keywords: Hydrodynamic, hydrogeochemistry action, hydrogeological condition, Jiyang county, shallow saline water.

\section{INTRODUCTION}

In North China inland plains, excess extraction of deep groundwater has caused the geological disasters [1-3]. Besides, saline water (TDS $>2 \mathrm{~g} / \mathrm{L}$ ) is widely spread [4-6] and a lot of saline water has not been fully taken advantage. The formation of the salt water is closely related to water circulation characteristics, aquifer lithology and diameter and discharge conditions [7]. In this paper, the inland area of Jiyang shallow brackish water dynamics and water chemical characteristics are analyzed to deepen the understanding of inland saline water formation mechanism and revolution laws and to provide scientific basis for salt water improvement $[8,9]$.

\section{METERIALS AND METHODS}

\subsection{Sample Collection and Test}

In inland saline water areas of Xiyan village in jiyang county, 9 wells were drilled. Electrical conductivity, PH, temperature and other conventional water quality indicators for different depth of drillings were monitored in real-time and long-term for 2 years, also the water level during the term. In 9\# drilling, the ammonium molybdate tracer were put in and the tracer experiment was carried out. 49 sampling points were arranged within the scope of the peripheral 2.5 $\mathrm{km}^{2}$ to control peripheral water quality change rule (Fig. 1).
Some water quality indicators were tested with the methods as following: Quantitative phase analysis by $\mathrm{D} /$ max-rB $\mathrm{X}$ ray diffractometer. Conductivity was determined by the conductivity meter of DDSJ-308A (intrinsic error $0.5 \%(\mathrm{FS})$ and Manta2 EUREKA's multiparameter. $\mathrm{PH}$ was determined by the portable $\mathrm{pH}$ meter of PHB-5 (resolution ratio: $0.01 \mathrm{pH}$ ). Conventional ionic terms were determined by double indicator and neutralization titration and $\mathrm{Na}^{+}$by the ionic meter of PXSJ-216F (resolution ratio:0.0001, error:0.3\%). $\mathrm{Mo}^{6+}$ ionic were tested by atomic absorption spectrophotometer - graphite furnace method (accuracy:0.005ppb).

\subsection{Data Processing}

Software such as Excel, AquaChem, GIS and SPSS were used to analyze of mathematical statistics on the test data and drawing.

\section{RESULTS AND DISCUSSION}

\subsection{Hydrogeological Condition}

\subsubsection{Aquifer Media and Dynamic Characteristics of Groundwater Level}

Taking inland area of Xiyan village in Jiyang county as an example, loose sediments was up to hundreds of meters in deep resulted from repeatedly diversion flood of Yellow River. According to the results of $X$ ray diffraction showed in Table 1, formation lithology was mainly fine sand and silt with multilayer structure vertically, also small thickness of single layer, and a plurality of layers of thin clay clip. 

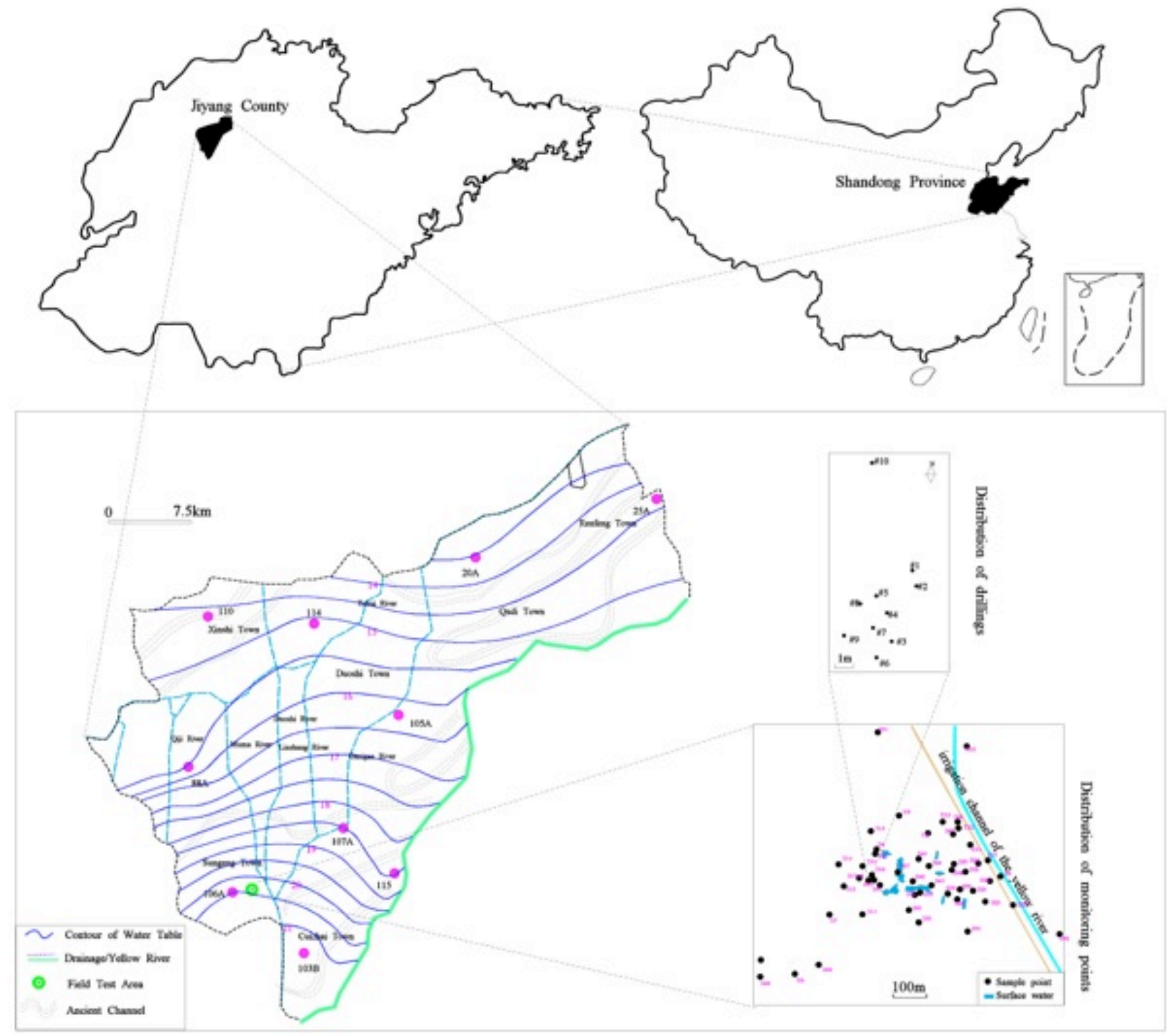

Fig. (1). Sketch of sampling points and hydrodynamic field.

Notably, clay content was relatively high and it was micro confined in partial section. Groundwater was mainly phreatic water of Quaternary pore fracture occurs in fissure clay, sandy loam and fine sand

In natural, groundwater table of inland saline water is shallow with buried depth being between $2 \sim 3 \mathrm{~m}$, which is less than the north evaporation limit depth of $3 \mathrm{~m}$. Therefore, evaporation concentration effect is strong. Influenced by precipitation, evaporation, surface drainage and human activities obviously, the groundwater presents typically “ weather - evaporation" type [10-12].

\subsubsection{Hydrdynamic Character}

From southwest to northeast, three ancient channels lying in the middle, south and northern fringe of Jiyang county respectively, where saline water and fresh water alternative distribution vertically with burial depth in $2 \sim 3 \mathrm{~m}$. The shallow groundwater movement direction and terrain slope were consistent, Fig. (2) in the direction of North East, and the hydraulic gradient was about $0.17 \%$. Vertical recharge and evaporation being the main supplementary way, the groundwater generated diffusion mixing with saline water locality, forming shallow island area of saline water, while

Table 1. $\mathrm{X}$ - ray diffraction analysis results of undisturbed soil.

\begin{tabular}{|c|c|c|c|c|c|c|}
\hline Mineral Species & $\alpha-\mathrm{SiO}_{2}$ & Kaolinite & Illite & Montmorillonite & Feldspar & Clay Minerals \\
\hline Mass Percent \% & 55 & 10 & 8 & 12 & 15 & 30 \\
\hline
\end{tabular}




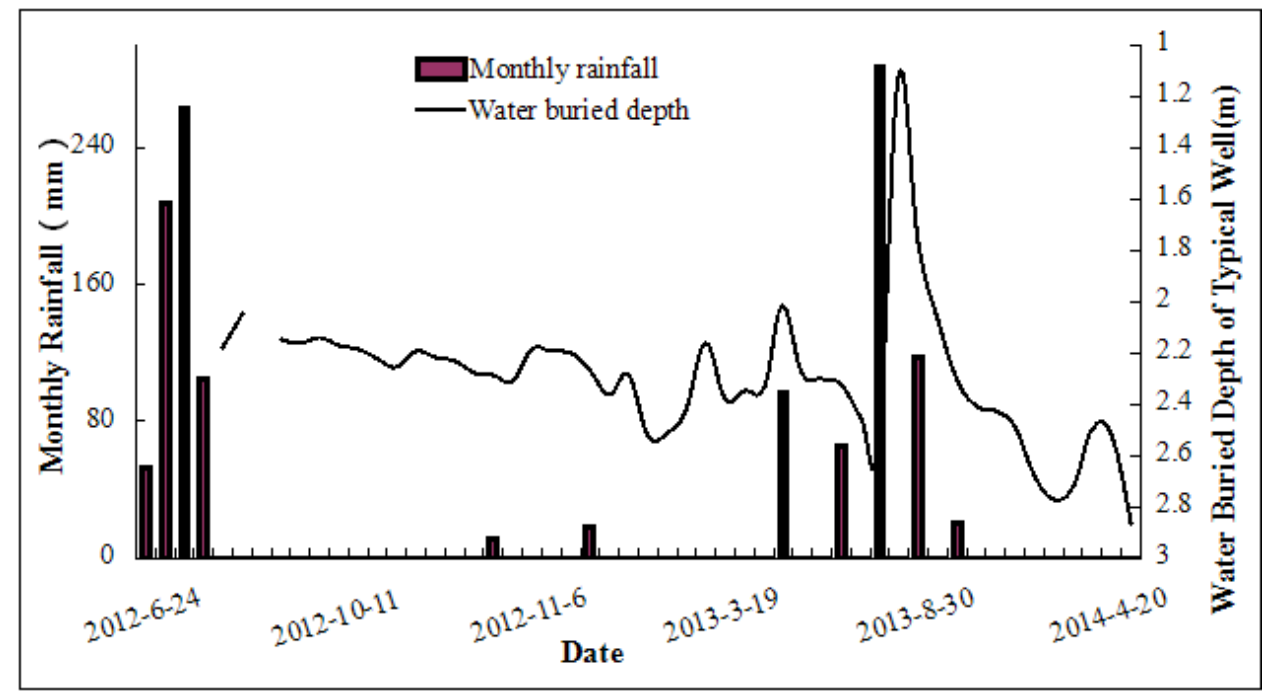

Fig. (2). Duration curve of shallow saline water buried depth and rainfall.

lateral runoff occurred only in the section of topography fluctuation such as ancient river band, along the Yellow river zone and other modern channel.

The ammonium molybdate tracer test show that the tracer concentration curve (Fig. 3) is the same type of the two symmetrical type, which is conform to the loose bed pore water aquifer concentration curve characteristics. The tracer diffusion adsorption by soil was slowly rise and decline slowly. It illustrated that groundwater source in the study area are the same. At the same time, the conductivity is obtained of $0.83 \mathrm{~m} / \mathrm{d}$. Owing to small hydraulic gradient, fine grading of aqueous medium particles and poor hydrodynamic condition, shallow groundwater circulation is weak and saline water is widely spread consequently.

\subsection{Hydrchemical Index Analysis}

Saline water quality analysis results of nine drilling in Sungeng town Jiyang county in period of 2012 2014 show that the average TDS is $11.9 \mathrm{~g} / \mathrm{L}$ and variable coefficient is $11 \%$. Among the cationics, $\mathrm{Na}^{+}$content is the highest followed by $\mathrm{mg}^{2+}$ and $\mathrm{Ca}^{2+}$ with average content of being $1691.79 \mathrm{mg} / \mathrm{L}, 1012.86 \mathrm{mg} / \mathrm{L}$, and $927.86 \mathrm{mg} / \mathrm{L}$ separately.
Among the anions, $\mathrm{Cl}^{-}$content is the highest followed by $\mathrm{SO}_{4}{ }^{2-}$ and $\mathrm{HCO}_{3}{ }^{-}$with average content of being 4402.82 $\mathrm{mg} / \mathrm{L}, 2808.32 \mathrm{mg} / \mathrm{L}$, and $856.75 \mathrm{mg} / \mathrm{L}$ separately.

While the percentage of MEQ of $\mathrm{Cl}^{-}$is the highest followed by $\mathrm{Na}^{+}$and $\mathrm{Ca}^{2+}$, among cationics, that of $\mathrm{Cl}^{-}$is over $50 \%$ among the anions to be the major cationics. Table 2. The $\mathrm{SO}_{4}{ }^{2-}$ and $\mathrm{HCO}_{3}{ }^{-}$are the second and third cationics (Fig. 4). Variable coefficient of $\mathrm{Na}^{+}$and $\mathrm{SO}_{4}{ }^{2-}$ are less than $10 \%$. In general, according to Shug Kalev classification, Jiyang shallow saline water chemical types presents $\mathrm{Cl}^{-\mathrm{SO}_{4}}{ }^{-}$ $\mathrm{Mg} . \mathrm{Na}$.type and Cl.SO 4 - Na.Mg type.

\subsection{Water Chemistry of Salt Formation}

\subsubsection{Evaporation and Concentration}

Inland plains climate is arid, and water bury in depth of $2 \sim 3 \mathrm{~m}$. Correlation research $[8,9]$ show that capillary water rising height is $3.4 \mathrm{~m}$ in shallow silt medium. Hence shallow groundwater migrate to the soil surface and participate in the strong evaporation under capillary force in the runoff lagging areas between ancient channels.

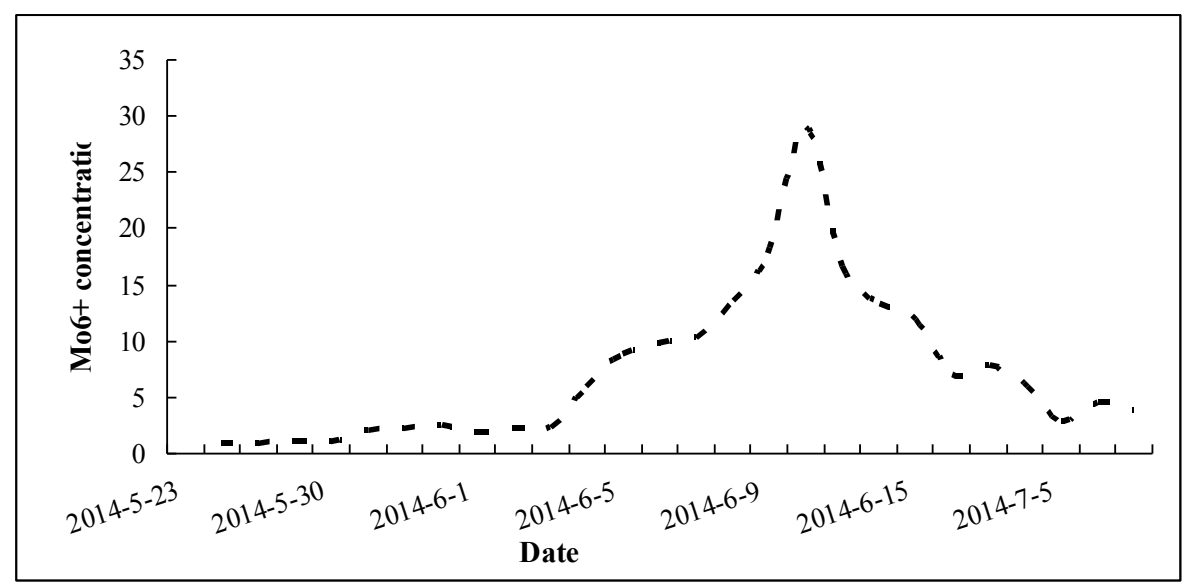

Fig. (3). Duration curve of the tracer concentration. 
Table 2. Ion composition characteristic value of shallow saline water in Jiyang County (n=10).

\begin{tabular}{|c|c|c|c|c|c|c|}
\hline \multicolumn{2}{|c|}{ Ion Composition } & \multirow{2}{*}{$\begin{array}{c}\text { Average } \\
1691.79\end{array}$} & \multirow{2}{*}{$\begin{array}{c}\text { Standard Deviation } \\
152.12\end{array}$} & \multirow{2}{*}{$\frac{\text { Max }}{1428.57}$} & \multirow{2}{*}{$\begin{array}{c}\text { Min } \\
1928.57\end{array}$} & \multirow{2}{*}{$\begin{array}{c}\text { Variable Coefficient } \\
0.09\end{array}$} \\
\hline & $m g / L$ & & & & & \\
\hline & $m e q / L$ & 73.56 & 6.61 & 62.11 & 83.85 & 0.09 \\
\hline \multirow{2}{*}{$\mathrm{Cl}$} & $m g / L$ & 4398.97 & 732.81 & 3282.15 & 5321.24 & 0.17 \\
\hline & $m e q / L$ & 123.91 & 20.64 & 92.45 & 149.89 & 0.17 \\
\hline \multirow{2}{*}{$\mathrm{HCO}_{3}^{-}$} & $m g / L$ & 856.75 & 38.93 & 815.15 & 939.54 & 0.05 \\
\hline & $m e q / L$ & 14.05 & 0.64 & 13.36 & 15.40 & 0.05 \\
\hline \multirow{2}{*}{$\mathrm{SO}_{4}^{2-}$} & $m g / L$ & 2808.32 & 207.00 & 2440.40 & 3074.91 & 0.07 \\
\hline & $m e q / L$ & 58.51 & 4.31 & 50.84 & 64.06 & 0.07 \\
\hline \multirow{2}{*}{$\mathrm{Ca}^{2+}$} & $m g / L$ & 927.86 & 112.92 & 735.58 & 1042.07 & 0.12 \\
\hline & $m e q / L$ & 46.39 & 5.65 & 36.78 & 52.10 & 0.12 \\
\hline \multirow{2}{*}{$\mathrm{Mg}^{2+}$} & $m g / L$ & 1012.82 & 147.47 & 792.47 & 1201.95 & 0.15 \\
\hline & $m e q / L$ & 84.40 & 12.29 & 66.04 & 100.16 & 0.15 \\
\hline \multirow{2}{*}{$K^{+}$} & $m g / L$ & 2.70 & 0.70 & 2.00 & 4.00 & 0.26 \\
\hline & $m e q / L$ & 0.07 & 0.02 & 0.05 & 0.10 & 0.26 \\
\hline$T D S$ & $m g / L$ & 11903.22 & 1359.93 & 9832.79 & 13460.18 & 0.11 \\
\hline
\end{tabular}

$\gamma \mathrm{SO}_{4} / \gamma \mathrm{Cl}, \gamma \mathrm{SO}_{4} / \gamma \mathrm{HCO}_{3}, \gamma \mathrm{Cl} / \gamma \mathrm{HCO}_{3}$ can be used to reflect the water quality of ion change trend in the process of evolution [10,11]. According to Fig. (5), value of $\gamma \mathrm{SO}_{4}{ }^{2-}$ $/ \gamma \mathrm{HCO}_{3}{ }^{-}, \gamma \mathrm{Cl} / \gamma \mathrm{SO}_{4}$ and $\gamma \mathrm{Cl} / \gamma \mathrm{HCO}_{3}$ is $3.3 \sim 4.5,6.1 \sim 10.9$ and $6.2 \sim 10.9$ severally, which are bigger than 1 . It illustrates that in long term process of soluble salt accumulation, shallow groundwater quality may tend to salty and $\mathrm{SO}_{4}{ }^{2-}$ accumulates faster than $\mathrm{HCO}_{3}{ }^{-}$.

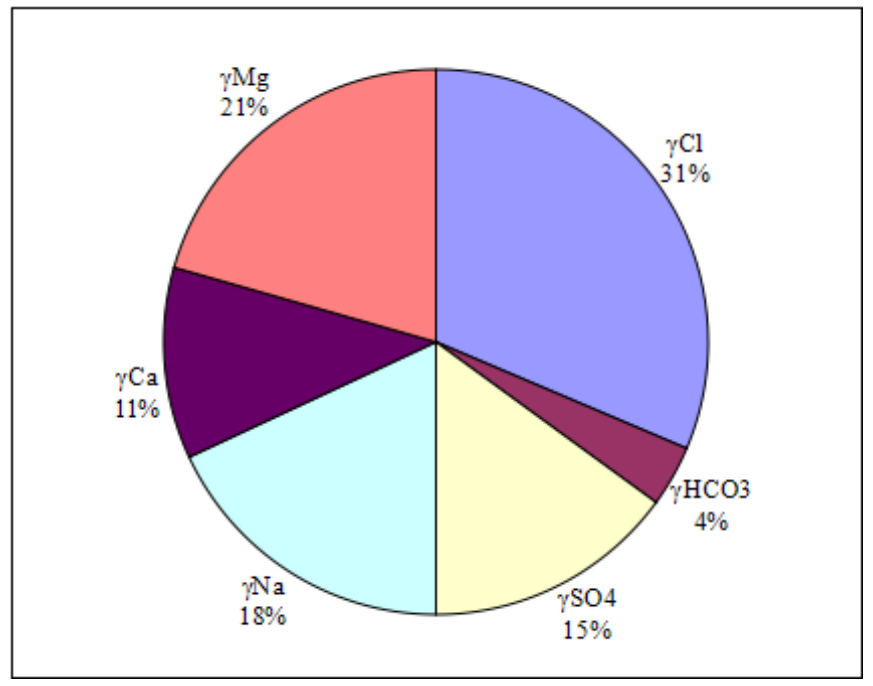

Fig. (4). MEQ percentage of conventional ions of shallow saline water in jiyang county.

\subsubsection{Action of Cation Exchange}

$\gamma \mathrm{Ca} / \gamma \mathrm{Na}, \gamma \mathrm{Mg} / \gamma \mathrm{Na}$ coefficient can be used to judge whether the ion exchange reaction is possible or not and analyze the water revolution process further. Data show that $\gamma \mathrm{Ca} / \gamma \mathrm{Na}, \gamma \mathrm{Mg} / \gamma \mathrm{Na}$ coefficient are little and the former is more little than latter. It reveals that mineralization degree of shallow groundwater is high especially $\mathrm{Na}^{+}$which is the advantage ion. Action of cation exchange of $\mathrm{Na}^{+}-\mathrm{Ca}^{2+} / \mathrm{Mg}^{2+}$ maybe happen.

$$
\begin{aligned}
& 2 \mathrm{Na}^{+}+\mathrm{CaX} \Leftrightarrow 2 \mathrm{NaX}+\mathrm{Ca}^{2+} \\
& 2 \mathrm{Na}^{+}+\mathrm{MgX} \Leftrightarrow 2 \mathrm{NaX}+\mathrm{Mg}^{2+}
\end{aligned}
$$

Besides, as one of the contributing factor coefficient of groundwater, $\gamma \mathrm{Na} / \gamma \mathrm{Cl}$ coefficient can be used to characterize concentration degree of $\mathrm{Na}^{+}$in groundwater. $\gamma \mathrm{Na} / \gamma \mathrm{Cl}$ coefficient of sea water is 0.85 . Water of low TDS presents high $\gamma \mathrm{Na} / \gamma \mathrm{Cl}$ coefficient being over 0.85 while water of high TDS is opposite being less than 0.85 .

Data being analyzed, $\gamma \mathrm{Na} / \gamma \mathrm{Cl}$ coefficient is $0.34 \sim 0.46$ being smaller than 0.85 , which illustrates cation exchange action of $\mathrm{Na}^{+}$exchanging with $\mathrm{Ca}^{2+}$ and $\mathrm{Mg}^{2+}$ in the formation occurred. Thus, $\mathrm{Ca}^{2+}$ and $\mathrm{Mg}^{2+}$ content in groundwater increase and $\mathrm{Na}^{+}$content decrease. Finally, $\gamma \mathrm{Na} / \gamma \mathrm{Cl}$ coefficient in shallow groundwater is smaller than that in seawater. Based on Fig. (6), $\gamma \mathrm{Na} / \gamma \mathrm{Cl}$ coefficient of inland shallow groundwater has a linear relation with TDS and the correlation coefficient is 0.9. With the TDS increasing, $\gamma \mathrm{Na} / \gamma \mathrm{Cl}$ coefficient decreased. What has been discussed above revealed that $\mathrm{Na}^{+}-\mathrm{Ca}^{2+} / \mathrm{Mg}^{2+}$ cation exchange acutely in the process of shallow groundwater salty.

\subsubsection{Action of Lioxiviation}

The content of $\mathrm{Mg}^{2+}$ is more than that of $\mathrm{Ca}^{2+}$ with $\gamma \mathrm{Mg} / \gamma \mathrm{Ca}$ approximately being 5.5 in seawater. General groundwater could not reach such a high value of $\gamma \mathrm{Mg} / \gamma \mathrm{Ca}$ [12]. In study area, value of $\gamma \mathrm{Mg} / \gamma \mathrm{Ca}$ in shallow groundwater is $0.9 \sim 1.2$, which is less than 5.5 . This 


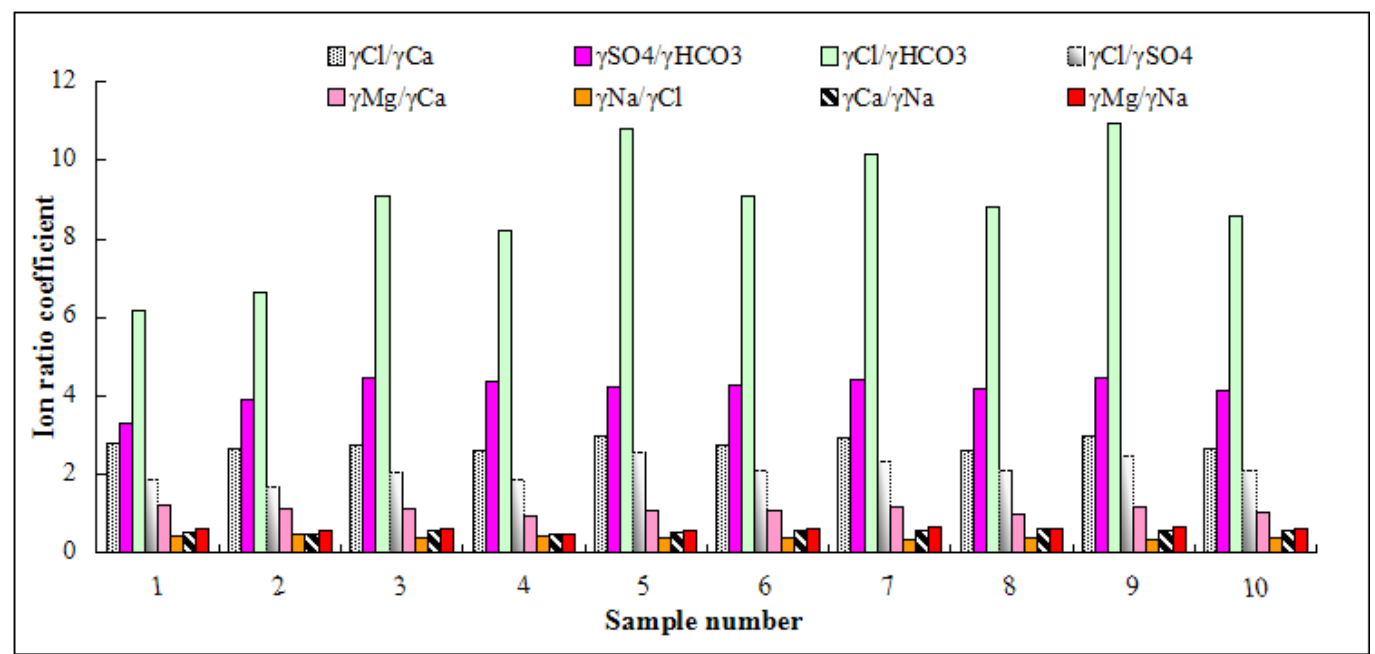

Fig. (5). Comparison diagram of ion proportionality coefficient.

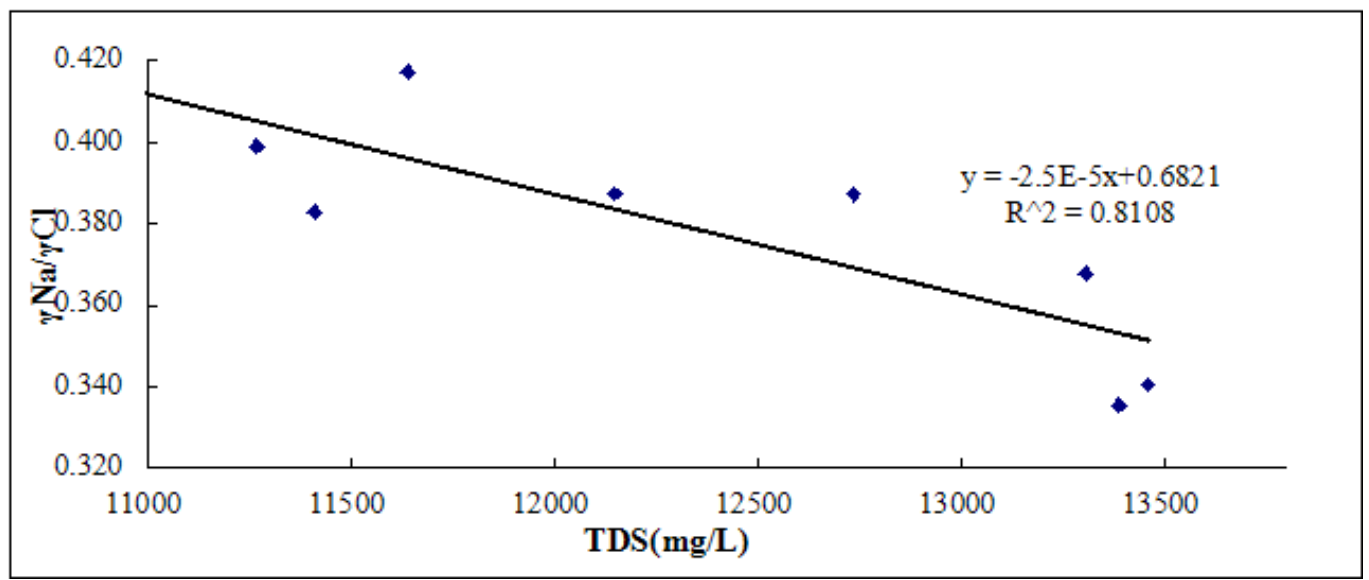

Fig. (6). Correlation curve of $\gamma \mathrm{Na} / \gamma \mathrm{Cl}$ and TDS of shallow saline water in jiyang.

illustrates the formation of salt water in the area is affected by action of continental lixiviation.

$$
\begin{aligned}
& \mathrm{CaSO}_{4} \cdot 2 \mathrm{H}_{2} \mathrm{O} \text { (gypsum) } \rightarrow \mathrm{Ca}^{2+}+\mathrm{SO}_{4}{ }^{2-}+2 \mathrm{H}_{2} \mathrm{O} \\
& \mathrm{CaCO}_{3}+\mathrm{H}_{2} \mathrm{O}+\mathrm{CO}_{2} \rightarrow \mathrm{Ca}^{2+}+2 \mathrm{HCO}_{3}{ }^{-}
\end{aligned}
$$

Inland shallow groundwater hydrochemistry type is complicated due to both lioxiviation and continental salinization. Several kinds of proportionality coefficients show that shallow saline water of study area is continental salinization cause influenced by a variety of water chemistry such as evaporation and concentration effect, stratum leached and the action of cation exchange. The chemistry type is complex. During the evolution, content of $\mathrm{HCO}_{3}{ }^{-}$, $\mathrm{Na}^{+}$tend to decrease and $\mathrm{Cl}^{-}, \mathrm{SO}_{4}{ }^{2-}$ tend to increase.

\section{CONCLUSION}

(1) Shallow saline water in the inland Yellow River Flood Plain is located in the runoff lagging areas between ancient channels with poor runoff and circulation condition. Poor runoff circulation condition and high clay content is conducive to the accumulation of salt. Water chemistry type is $\mathrm{Cl}^{-\mathrm{SO}_{4}}$ Mg.Na. and $\mathrm{Cl}_{\text {. }} \mathrm{SO}_{4}-\mathrm{Na} . \mathrm{Mg}$ type.
(2) During the process of inland shallow saline groundwater circulation, the intensifying interactions between water and aquifer media is apparent. Significant groundwater mineralization play a decisive role to the formation of the inland saline water body.

(3) Comprehensive analysis of conventional ion content and $\gamma \mathrm{Na} / \gamma \mathrm{Cl}, \quad \gamma \mathrm{Ca} / \gamma \mathrm{Na}, \quad \gamma \mathrm{Mg} / \gamma \mathrm{Na}, \quad \gamma \mathrm{Mg} / \gamma \mathrm{Ca}, \quad \gamma \mathrm{Cl} / \gamma \mathrm{HCO}_{3}$ coefficient shows that different hydrogeochemical action such as evaporation and concentration effect, stratum leached and the action of cation exchange is the basic reason of complex hydrochemistry type.

(4) In inland area, formation and evolution of the inland continental salinization saline groundwater hydrochemical field controled by groundwater flow paths, atmosphere, lithology, circulation depth and hydrogeochemical effect jointly. Just changing the condition of shallow groundwater runoff is not enough to improve shallow salt water.

\section{CONFLICT OF INTEREST}

The authors confirm that this article content has no conflict of interest. 


\section{ACKNOWLEDGEMENTS}

This paper is aided by the National Natural Science Foundation(41172222,41472216), Science and Technology Development Plan Project of Jinan (201303082) and Graduate Innovation Fund Project of University of Jinan (YCXZ13004).

\section{REFERENCES}

[1] Z. Zhang, "Investigation and Evaluation of Sustainable Utilization of Groundwater in North China Plain", Geological Publishing House, Beijing, 2011.

[2] B.X. Zhang, J.W. Huang, and M.H. Yang, "Problems and protection measures of water resources exploitation and utilization in Jiyang County", Water Resources Protection, vol. 21, no. 5, pp. 58-61, 2005.

[3] Y.H. An, F.C. Zhang, and X.J. Yao, "Distribution and evolution of the yellow river delta and groundwater as well as salts in the yellow river delta", Earth and Environment, vol. 3, pp. 65-70, 2006.

[4] C.R. Mou, and J.P. Zhang, "Analysis on the status and mechanism of brackish-water interface down in a typical area of Hebei province ", Hebei Water Resources and Hydropower Engineering Forum, vol. 1, pp. 37-3, 2002.

[5] Z.X. Zhang, and H.L. Zhang, "Space and time evolution of groundwater dynamic field in northwest plain in Shandong province", Shandong Land and Resources, vol. 27, no. 10, pp. 3134, 2011.

[6] X.N. Zhou, S.Y. Liu, and Z. Wang, "The chemical characteristics and available analysis of shallow groundwater in the typical area of plain of North China-take Hengshui in example", Water Sciences and Engineering Technology, vol. 2, pp. 56-59, 2008.

[7] X. Lu, A. Zhou, M. Wang, L. Yang, and H. Lu, "Characteristic analysis of phreatic water equality evolution by Piper diagram in Huaihe river drainage area, Jiangsu province" , Geotechnical Investigation \& Surveying, no. 2, pp. 42-47, 2010.

[8] Z.L. Shen, "Hydrogeochemical Basis", Geology Publishing House, Beijing, 1993.

[9] P. Zhang, H. Wu, and H. J. Yin, Research on the effects of the soil structure on the capillary water rise height and groundwater evaporation” , Water Saving Irrigation, no. 3, pp. 6-8, 2011

[10] P. Kroopnick, "The $\mathrm{SO}_{4}$ :Cl ratio in oceanic rain water, " Pac Sci. vol. 31, no. 1, pp. 91-106, 1977.

[11] N. C. Mondal, and V. P. Singh, "Determing the interaction between groundwater and saline water through groundwater major ions chemistry, "Journal of Hydrology, vol. 38, no. 2, pp. 100-111, 2010.

[12] Y. Rosenthal, and G.P. Lohmann, “Accurate estimation of sea surface temperatures using dissolution-corrected calibrations for $\mathrm{Mg} /$ Ca paleothermornetry, " Paleoceanography, vol. 17, no. 3, pp. $1-6,2002$.

(C) Fengjuan et al.; Licensee Bentham Open.

This is an open access article licensed under the terms of the Creative Commons Attribution Non-Commercial License (http://creativecommons.org/licenses/by$\mathrm{nc} / 3.0 /$ ) which permits unrestricted, non-commercial use, distribution and reproduction in any medium, provided the work is properly cited. 